\title{
The voice of nurse educators on teaching end of life care in U.S. schools of nursing
}

\author{
Vidette Todaro-Franceschi ${ }^{1}$, Adrial A. Lobelo \\ 1. Hunter College, City University of New York, New York, USA. 2. South Beach Psychiatric Center, Staten Island, NY, USA. \\ Correspondence: Vidette Todaro-Franceschi. Address: 425 East 25th St, New York, NY 10010. \\ Email: vtodaro@hunter.cuny.edu
}

Received: December 1, 2013

Accepted: January 25, $2014 \quad$ Online Published: February 23, 2014

DOI : 10.5430/jnep.v4n4p165

URL: http://dx.doi.org/10.5430/jnep.v4n4p165

\begin{abstract}
Background: End of life care (EOLC) education is important for those engaged in the caring professions. In 1997 the principal investigator (PI) for this study, working as a nurse educator, noted that there was no EOLC in the undergraduate program in her school of nursing, and she began to incorporate content into her teaching. She was not alone; over a decade ago it was identified by the American Association of Colleges of Nursing (AACN) that there were deficiencies in EOLC nursing education. AACN worked with the City of Hope National Medical Center to form the End of Life Nursing Education Consortium (ELNEC) to help address the pedagogic insufficiency. The PI was in the first ELNEC Trainer cohort in 2001 and has been to several other ELNEC conferences since then. The author's experiences with the integration of EOLC education, along with ongoing commentary from other nurse educators at various conferences and seminars, prompted this study.
\end{abstract}

Methods: This was an exploratory descriptive study in which nurse educators in U.S. schools of nursing were invited to participate in a survey to elicit information regarding the current state of end of life care (EOLC) education in their respective school programs. A survey was developed and after IRB approval was emailed in several phases to academic nursing programs throughout the United States. Among respondents who met inclusionary criteria for the survey, 233 completed the survey. Survey participants were anonymous and were also invited to provide commentary and recommendations. Analysis-synthesis of qualitative data was done to identify if there were any themes.

Results: Two hundred and four participants responded to the question of whether they had been able to integrate EOLC content into their respective programs and 138 answered in the affirmative, although almost all of the participants, even those who claimed some success in the integration of EOLC content, shared having met with various obstacles. How much EOLC education was integrated and what was actually taught varied considerably. Significant barriers to EOLC education were identified by many respondents and recommendations for improvement were offered.

Conclusions: Nurse educators need to champion EOLC education in schools of nursing to ensure that nurses today and tomorrow will be prepared to provide the quality care that society deserves.

\section{Key words}

End of life care education, Nursing education, Death education, Nursing curriculum integration 


\section{Introduction}

It has been well over a decade since the American Association of Colleges in Nursing (AACN), in collaboration with the City of Hope (COH) National Medical Center, formed the End of Life Nursing Education Consortium (ELNEC) to address deficiencies in EOLC nursing education in the U.S. ${ }^{[1]}$. Initially funded by the Robert Wood Johnson Foundation and led by nurse scientist palliative care pioneer Dr. Betty Ferrell, the program has had great success and there are currently well over 15,000 nurses who have become ELNEC Trainers ${ }^{[2]}$. Those trainers have in turn gone on to train nurses, would-be nurses, along with ancillary staff, physicians, social workers, psychologists and clergy in the basic EOLC competencies necessary to provide quality care to the dying and their loved ones.

The principal investigator (PI) for this study was in the first cohort of nurses in 2001 to be supported by the Robert Wood Johnson Foundation fellowship to become an ELNEC Trainer. As a new faculty member in 1997, with a practice background in critical care, she had noted that there was very little, if any, specific EOLC content in the undergraduate and graduate curriculums and she embarked on an effort to address the deficiency. Originally integrating EOLC only in courses she taught, in 2000 she resurrected an old elective course on death and dying. However, getting the course to be offered on a regular basis was difficult due to purportedly limited resources and faculty being needed to teach other courses. Thus, she later wrote an entirely new EOLC course that met pluralism and diversity requirements, and was writing intensive, with the hope that it would be offered more frequently. Since its inception over a decade ago, this elective course has been an especially popular one, with enrollment typically running from 60 to 80 students, and there are always requests to over tally beyond the student limit. One year a group of approximately 70 students petitioned to have the course offered, to no avail. Consequently that particular cohort of students never had the opportunity to take the class.

After becoming an ELNEC Trainer, beginning in the fall of 2001 the PI formally integrated all of the ELNEC core program modules (at the time there were 9; today there are 8) into the undergraduate generic and graduate adult health clinical nurse specialist programs. She was supported by administration and colleagues to integrate all of the ELNEC modules, although instead of the content having a dedicated time and place in the undergraduate curriculum, it was discontinuously placed in various courses over the junior and senior years. Not only did this dilute the EOLC content, it created planning and scheduling issues for multiple faculty involved in teaching the core courses, having to plan dates and times to teach, as well as test items for many exams in the various courses. Hence, despite efforts, there remained significant challenges related to teaching EOLC.

Almost 50 years ago, palliative care nurse scientist and pioneer, Jeanne Quint ${ }^{[3]}$, also known as Jeanne Benoliel, in her studies of EOLC nursing education, noted:

When and how nurse students encounter dying patients and what they are taught about death depends on several factors-ideology of the school, the organization of course work and practice opportunities, the rationale underlying the use of patients as assignments, the settings used for practice, and the approaches used to teach about the care of dying patients (p.19) ${ }^{[3]}$.

This statement is no less accurate today. Accordingly, the researchers set out to explore how EOLC is currently being integrated in nursing schools in the U.S. and to identify what, if any, difficulties might remain, regarding the teaching of EOLC.

\section{Methods and procedures}

An exploratory descriptive approach was used for this study. A survey was designed to explore the current state of EOLC nursing education. After IRB approval, volunteers were recruited via email invitation from a listing of ELNEC trainers (n $=1622$ ) and then a second phase invitation was emailed out to deans and directors in schools of nursing throughout the U.S. $(n=1685)$ from the American Association of Colleges of Nursing (AACN) and the National League of Nursing 
(NLN) lists of accredited nursing programs. The deans and directors were asked to forward the invitations to faculty who teach EOLC in their schools.

Participants were informed about the purpose of the study and the confidentiality measures in effect. Completion of the survey was taken as participant consent to participate. No compensation was provided for participating in the study.

The survey was administered using Survey Monkey web-based technology encrypted to ensure confidentiality. It included demographic questions (sex, age, educational level, geographic location, program teaching in, etc.) and questions specific to EOLC education. The questions regarding EOLC education were detailed to gain knowledge of EOLC content integration in the core curricula, what topics, if any, had been integrated, availability and frequency of EOLC electives, and whether participants perceived overall EOLC education to be sufficient in their respective programs. At the conclusion of the survey, participants were invited to offer additional commentary regarding EOLC education in their respective schools, along with recommendations for future curriculum planning. Separate thematic analysis-synthesis of this additional data was performed ${ }^{[4]}$.

\section{Results}

Four hundred and fourteen EOLC educators throughout the U.S. responded to the invitation to participate; however, only 235 of the participants met the inclusion criteria of being faculty who currently teach in schools of nursing; 233 completed the survey in its entirety (224 females, 9 males; 228 were ELNEC Trainers). Participants represented all U.S. states with the exception of Alaska, Hawaii, Maryland, Utah, and Wyoming. The highest representation came from California $(\mathrm{n}=$ 26), New York $(n=14)$ and Ohio $(n=13)$. Many of the participants reported teaching in both undergraduate and graduate programs (see Table 1). While two hundred and thirty three nurse educators completed the survey, the number of responses to survey questions varied (as per IRB protocol, there were no forced answer settings). A majority of the participants $(n=204)$ responded to the question of whether they had been able to integrate EOLC content into their respective programs and 138 answered in the affirmative. How much EOLC education was integrated and what was actually taught varied considerably (see Table 2).

The majority of the participants $(n=204)$, even those who claimed some success in the integration of EOLC content, noted that they had met with various obstacles in trying to get EOLC education into their respective programs. Several salient themes emerged in the analysis-synthesis as barriers to the incorporation of EOLC education, with the most prominent being faculty resistance, inadequate support from administration, and lack of classroom time to devote to the subject (see Table 3).

Table 1. Participant Demographics $(\mathrm{n}=233)$

\begin{tabular}{|l|l|}
\hline $96 \%$ Female & \\
$4 \%$ Male & \\
56 years old (mean age) & $50.4 \%$ Master's Degree in Nursing \\
$93.1 \%$ White & $34.5 \%$ Doctorate in Nursing \\
$2.6 \%$ Asian & $15.1 \%$ Doctorate in other areas \\
$1.3 \%$ Black & \\
$1.3 \%$ Hispanic & 17.2 Years of teaching experience (mean) \\
$1.7 \%$ Other & 12.4 Years teaching in current nursing program (mean) \\
$81 \%$ Christian & \\
$5.2 \%$ Agnostic & \\
$3.0 \%$ Jewish & \\
$10.8 \%$ Other & \\
\hline
\end{tabular}


Table 2. Content Taught

\begin{tabular}{ll}
\hline Topical Content ${ }^{*}$ & Included in Curricula \\
\hline Introduction to EOL care & $79.6 \%$ \\
Pain management & $83.0 \%$ \\
Symptom management & $77.4 \%$ \\
Legal and ethical issues & $82.4 \%$ \\
Cultural aspects & $73.4 \%$ \\
Communication & $84.1 \%$ \\
Grief and Bereavement & $78.9 \%$ \\
Final Hours & $66.9 \%$ \\
\hline
\end{tabular}

*Topical outline coincides with ELNEC Modules 1-8

Table 3. The Voices of Nurse Educators

"Our denial of death influences our nursing education choices ... We devote entire courses and textbooks to the beginning of life, but only a fraction [is devoted] to the end of life ... This is disproportionate to the number of nurses who provide care in obstetrics compared to those nurses involved in the care of dying patients."

“Colleagues believe it is 'specialty content'! They cannot see why this content is 'more important' than other specialty content (ER, ICU, gerontology, or genomics).”

"There is so much content we want to teach our students it is hard to get it all in. Teaching an EOLC elective was the only way to really offer this information to our students ....”

"There is NO integration. Because I routinely teach the one course where faculty can choose the topic I include EOLC there. However, about a third of our students each year take an international trip instead of the course and so [those students] are exposed to no organized classroom EOLC content.”

"I think all nursing organizations/Boards of Nursing should mandate EOLC as a separate course for all schools of nursing - we all go through an OB rotation, and not all of our patients have babies!!! BUT ALL of our patients will die!! This is a vitally important subject and nurses should lead the way in EOLC!”

\section{Faculty colleague resistance}

The most frequently cited barrier to integrating EOLC content was faculty resistance/lack of support. While more than two-thirds of participants were able to incorporate EOLC content into their basic programs, many indicated that it was a challenge due to significant colleague resistance. For example, one participant shared how colleagues said that EOLC was thought to be "specialty content" better relegated to an elective course offering. Another participant had been told that "EOLC was 'common sense' and did not need a special emphasis." Still others voiced that "politics and territoriality" among colleagues who were team-teaching courses was a particularly thorny problem. To protect respective "teaching turf," one participant found it easiest to incorporate EOLC only into her courses. Several participants shared that when they taught a particular course they discussed EOLC; however, when other colleagues taught the same course, EOLC topics were frequently omitted.

One participant viewed the lack of EOLC faculty buy-in as a reflection of the "fear of a political backlash" from an administration focused on NCLEX scores and technical skills. Some faculty members voiced that their colleagues consider EOLC content to be in direct competition with content that is emphasized on the NCLEX licensing exam.

\section{I nadequate administrative support}

Some participants shared instances where a lack of administrative support resulted in little to no EOLC integration in their curricula. One participant shared developing an elective EOLC course, which was met with tepid support from her program's administration. Several participants were informed by their respective administrators that EOLC content was equivalent to 'hospice care' and 'specialty course' curricula. Others voiced the challenge of getting their leadership to view EOLC content as equally relevant to practice, on par with all other general nursing education requirements. Another 
apparently common, although erroneous belief, that "EOLC content is not on the NCLEX [licensing exam]," was often cited by participants as contributing to the lack of administrative support.

\section{Lack of classroom time}

Time constraints are always an issue in nursing curricula. One hears repeatedly from nurse educators that there is not enough time to teach topics that are believed to be important. With ever-increasing knowledge there is more to teach (and learn), and consequently less time to do it. One participant, an ELNEC trainer, wrote, "We have 2 lectures in medicine/ surgery specifically focusing on EOLC issues, but we don't have the time to utilize all of the ELNEC content."

Faculty at traditional BSN programs in liberal art colleges have argued that nursing courses and nursing electives must compete with all other general education requirements that students need to meet (e.g., foreign languages). Compounding the issue is the merger of instructional units, resulting in students taking a one-credit course, when the material covered in that course was once offered in a two- or three- credit course. The growth in the past decade of accelerated BSN programs for second degree students and career changers has compounded the problem of trying to integrate EOLC content due to an already densely packed curriculum.

\section{Other voiced barriers}

Only a few participants $(n=3)$ shared that EOLC was taught in a separate required course. In addition, more than half (57\%) disclosed that their respective nursing programs do not offer any elective EOLC course. In schools where there was an EOLC elective, many participants noted that the course may not be offered every term or even every year, depending on faculty and financial resources.

High faculty turnover was another reported factor in implementing and sustaining EOLC education. One program had a faculty turnover rate of $75 \%$ in eight years, mostly due to retirements. It was noted by several participants that content continuity in programs is difficult to attain with high faculty turnover.

A number of participants voiced that the emphasis on using simulation to teach has affected what is being taught in their respective programs. A few noted that the need to maximize time in honing students' technical skills has become increasingly apparent, having a negative impact on the time allocated for other essential content.

\section{Recommendations for curriculum integration of end of life care education}

Nearly two-thirds of the participants perceived that the EOLC education offered in their respective nursing programs is insufficient. This is not surprising since those surveyed are naturally supporters of EOLC education; however, exploring their voiced concerns about obstacles to teaching EOLC is necessary if we are to improve care of the dying and their loved ones. Participant recommendations for future curriculum planning include, but are not limited to: full faculty discussion/ buy in, a required EOLC course, or at minimum better integration of content, elective offerings, ongoing evaluation of what is being taught, and more administrative support.

Faculty that appeared to have had the most success in EOLC curriculum integration were located in schools where there were multiple ELNEC-trained faculty. One participant reported there were four faculty members who are ELNEC trainers in her school and these faculty members not only integrated ELNEC into the curriculum, but also hold regular continuing education offerings for the nursing workforce in their community. The need for faculty "champions" to systematically coordinate and implement EOLC in their respective curricula was cited by several participants. The designated faculty champions would ideally be ELNEC-trained or hospice/palliative care certified. They would be empowered to serve as curriculum consultants with the additional aim of tackling faculty resistance to change. 
Another recommendation is for the EOLC material that is purportedly on the NCLEX, to be more clearly specified in the detailed NCLEX exam blue print and in NCLEX review books. A quick glance at several review texts indicates that EOLC and palliative care are not especially prominent topics. This would help to correct the misperception by some faculty who believe that EOLC/palliative care is not on the NCLEX. It was also noted that students who reported back to faculty after taking the exam frequently said that there were no EOLC/palliative care questions on the exam. Nurse educators need to ensure that would-be nurses are consistently tested on EOLC content in order to reinforce its importance.

\section{Limitations of the study}

Many of the original email addresses from the lists of ELNEC trainers were no longer accurate, and for the second phase, involving a third party (the deans/directors) as a way to recruit participants was not ideal. It is impossible to know whether or not those who didn't participate did so due to individual choice or because they may not have received an invitation. There is also the possibility that many schools of nursing do not have faculty who are specifically designated to teach EOLC.

Variable number of responses to questions posed is always a concern with surveys. In Survey Monkey, there is a mechanism to force an answer for each question before participants can proceed to the next question. But, according to ethical standards, this is not acceptable; research participants should always have a choice in their participation. Consequently, there were a few omissions. One could speculate as to why this might be the case, as one could wonder why the overall number of participants was low. Is it possible that there might be schools that have such limited EOLC content in their curricula that there are no identified educators to teach it? Is it possible that interested faculty were afraid to respond to questions as one participant noted, for fear there might be "backlash?” These and other questions should be pondered at this juncture, where there are glaring and continued inadequacies in health care related to care of the dying and their loved ones.

\section{Discussion and implications}

Nursing school faculty who have successfully integrated EOLC into their core curricula and/or created an EOLC elective have had their efforts validated by improved student attitudes toward dying, death and EOLC-related issues. Some research has shown that a significant relationship exists between perceptions of preparedness and ability to care for the dying and the nurse's ways of being in the world along with their professional quality of life ${ }^{[5,6]}$. Other studies have shown that death attitudes and power (as knowing participation in change) were also significantly different along with diminished death anxiety after receiving EOLC education ${ }^{[7-9]}$.

That the lack of preparedness to care for the dying and their loved ones may result in poor professional quality of life for nurses warrants further reflection; nurse leaders and educators cannot afford to ignore the call to action. With the prevalent and increasing incidence of compassion fatigue and burnout in nursing today, and its evident concurrent effects on quality and safety in practice, the fact that nurse educators can lessen the incidence of compassion fatigue through better educational preparation to care for the dying is not only very appealing, but indeed obligatory ${ }^{[10]}$.

Many nursing programs do not have elective course offerings on EOLC, and some participants noted it would be pointless to create them if there were no administrative support and faculty resources to teach the courses on a regular basis. Nurse educators and administrators must also consider the fact that if EOL and palliative care are offered as elective rather than required courses, many nurses and nursing students will likely choose not to take the course, for given an option, a lot of people prefer not to discuss EOLC topics. Learning to face dying and death should not be optional for health care professionals since they will all have to do it, both personally and professionally. And it is nurses who are the health care professionals most often at the bedside rendering care to patients who are dying and their loved ones. 
In re-visioning our undergraduate program over the past several years, we have addressed the need for EOLC to have its own designated space and time in our program; there will be a full term 3-credit required course that covers foundations of both ethics and EOLC. The PI is grateful to our dean and the faculty for having the vision to move this new curriculum forward. But the authors ponder why it took so long. That it has taken 16 years at one school of nursing to get a dedicated time slot for this vital content, with much effort and wheel spinning, and given that many nurse educators in schools of nursing throughout the country continue to voice significant barriers, attests to the need for further exploration.

Additional formal study of the current state of EOLC nursing education is needed; however, school responsiveness plays a part in getting an accurate picture of how well our workforce is being prepared. In medicine, attempts to formally study the current state of EOLC and palliative care pedagogy seem to have fallen short due to the complex nature involved in attaining data. It is especially difficult if no one person is responsible for the coordination and teaching of this content. A case in point was the survey done by Van Aalst-Cohen, Riggs, and Byock ${ }^{[11]}$, in which they noted a very poor response rate from U.S. medical schools.

All human beings will die, and chances are it will continue to be nurses who are the caregivers at the end of life for the majority. A disservice is committed to patients, their families, nursing colleagues, and nurses-to-be when EOLC education is not adequately provided. Undoubtedly, EOLC education needs to become a mandatory, consistently taught part of health professional education. For now, this study offers some insight into the current state of EOLC education in U.S. schools of nursing. The voices of those nurse educators who would teach (or are teaching) EOLC and palliative care around the country beseech us to sit up and take notice. Recognition of nursing's significant role in EOLC needs substantial endorsement and continued advocacy by the profession.

\section{References}

[1] American Association of Colleges of Nursing and the City of Hope National Medical Center. End-of-Life Nursing Education Consortium (ELNEC) Curriculum. 2000; Washington, DC: American Association of Colleges of Nursing.

[2] End of Life Nursing Education Consortium (ELNEC). History, statewide effort and recommendations for the future: Advancing palliative nursing care. 2012; Available from: http://www.aacn.nche.edu/elnec/publications/ELNEC-Monograph.pdf

[3] Quint, JC. The nurse and the dying patient. 1967; New York: Macmillan.

[4] Pope, C, Mays, N, Poppay, J. Synthesizing qualitative and quantitative health research: A guide to methods. 2008; New York: McGraw-Hill.

[5] Todaro-Franceschi, V. Changing the face of death: A pedagogic intervention. Journal of Professional Nursing. 2011; 27(5): 315-319. http://dx.doi.org/10.1016/j.profnurs.2011.04.002

[6] Todaro-Franceschi, V. Critical care nurse perceptions of preparedness and ability to care for the dying and their professional quality of life. Dimensions of Critical Care Nursing. 2013; 32(4): 184-190. http://dx.doi.org/10.1097/DCC.0b013e31829980af

[7] Callahan, MF, Breakwell, S, Suhayda, R. Knowledge of palliative and end-of-life care by student registered nurse anesthetists. American Association of Nurse Anesthetists Journal. 2011; 79(4 Suppl): S15-S20.

[8] Dobbins, EH. The impact of end-of-life curriculum content on the attitudes of associate degree nursing students toward death and care of the dying. Teaching and Learning in Nursing. 2011; 6(4): 159-166. http://dx.doi.org/10.1016/j.teln.2011.04.002

[9] Todaro-Franceschi, V \& Spellman, M. End of life pedagogy, death attitudes and power as knowing participation in change. Journal of Nursing Education and Practice. 2013; 3(1): 120-125.

[10] Todaro-Franceschi, V. Compassion fatigue and burnout in nursing: Enhancing professional quality of life. 2013; New York: Springer.

[11] Van Aalst-Cohen, ES, Riggs, R, \& Byock, IR. Palliative care in medical school curricula: A survey of United States medical schools. Journal of Palliative Medicine. 2008; 11: 1200-1202. http://dx.doi.org/10.1089/jpm.2008.0118 